\title{
Notícia: Segunda Conferência Internacional Reconstruindo a Psicologia da Saúde ${ }^{1}$
}

\author{
Tereza Cristina Cavalcanti Ferreira de Araujo $^{2}$ \\ Universidade de Brasília

\section{News: Second International Conference on Reconstructing Health Psychology}

Entre 23 e 25 de agosto de 2001, foi organizada a Segunda Conferência Internacional Reconstruindo a Psicologia da Saúde na Aston University, em Birmingham, Inglaterra, com a participação de representantes de 13 países. Este encontro, presidido por David Marks, editor do Journal of Health Psychology, deu continuidade às discussões sobre o desenvolvimento teórico, metodológico e assistencial da Psicologia da Saúde instauradas por ocasião do evento anterior realizado no Canadá.

Dentre os trabalhos desenvolvidos em diversos centros internacionais de pesquisa, vale destacar a instigante apresentação de Doug Carroll (University of Birmingham) que propôs uma meta-análise de pesquisas longitudinais, que adotaram metodologias quantitativas em uma tentativa de estabelecer associação entre saúde e estresse. Ao comparar os dados obtidos na América do Norte junto a sujeitos acometidos por doenças coronarianas, um ano após o episódio crítico, com os equivalentes levantados no Reino Unido, não foi possível verificar correlação positiva entre depressão e ansiedade com mortalidade. Se na investigação norte-americana foram identificados sintomas de depressão e ansiedade, os quais foram associados ao aumento da mortalidade, todavia estudo semelhante desenvolvido na Escócia não conduziu a tal comprovação. Do mesmo modo, em uma extensa investigação, ao longo de duas décadas, junto a mais de 6.500 indivíduos, não foi possível prever mortalidade a partir de indicadores de estresse inicialmente detectados. O pesquisador alerta para os vieses metodológicos dessas investigações e critica a negligência quanto à influência de fatores culturais na definição das noções implicadas em projetos de saúde. Em síntese, certamente doença grave pode estar associada à mortalidade, mas não necessariamente depressão, ansiedade e estresse. Considerando as medidas priorizadas pelos programas de saúde em diferentes países a partir das informações propaladas por tais investigações, o alerta de Doug Carroll parece fundamental e, uma vez mais, aponta para a necessidade de trabalhos de meta-análise semelhantes.

1 Os interessados em acompanhar os trabalhos dos conferencistas ou fazer contato com o grupo podem consultar a página www.med.mun.ca/ health01.

2 Endereço: UnB, Instituto de Psicologia, Brasília, DF, 70910-900 E-mail:araujotc@unb.br.
Catherine Campbell (London School of Economics) em sua palestra sobre programas de prevenção do HIV na África do Sul, conclamou a colaboração estreita entre psicólogos da saúde acadêmicos e ativistas da saúde para que seja possível ampliar a compreensão sobre comportamentos de saúde, evitando-se os riscos das idéias críticas sem ações críticas. Com experiência de intervenção junto a uma comunidade caracterizada por altos níveis de pobreza, desigualdade de gênero, conflitos étnicos e violência (30\% dos trabalhadores nas minas e 60\% das mulheres jovens na África do Sul são portadores do HIV), Campbell insiste sobre a necessidade da renegociação coletiva das identidades sociais e sexuais e no desenvolvimento do senso de controle da saúde desses grupos e de seus membros. Visando a conquista dos "meios de capacitação" e da consciência crítica, sobretudo pelos segmentos sociais atingidos pela marginalização no mundo globalizado, sugere intervenções à luz da perspectiva de Paulo Freire.

Para David Marks (City University of London), é possível distinguir três principais abordagens atuais na área. A primeira, e provavelmente a mais amplamente difundida, corresponde à Psicologia da Saúde Clínica, caracterizada por ações no âmbito do sistema de saúde, ou seja, hospitais, clínicas e centros de saúde. Está voltada, principalmente, para grupos de pacientes com disfunções específicas, tais como diabetes e câncer. Além da intervenção terapêutica, busca otimizar os serviços prestados através do planejamento de pesquisas com enfoque predominantemente quantitativo e quasi-experimental. A segunda abordagem destina suas ações para a melhoria da saúde da população em geral, mas acaba por focalizar grupos vulneráveis e de risco em sua perspectiva de cunho preventivo. Utiliza métodos epidemiológicos e visa a avaliação dos programas implementados, podendo ser denominada Psicologia da Saúde Pública. E por fim, a Psicologia da Saúde Comunitária, cujas propostas de promoção da saúde mental e física estão direcionadas para famílias e comunidades, visando à emancipação e mudança social. Emprega uma abordagem multi-metodológica, associando pesquisadores, profissionais e representantes comunitários.

Michael Murray (Memorial University of Newfoundland) defendeu a revitalização da Psicologia da Saúde. Nesse sentido, tanto pesquisador quanto sujeito participante têm papel fundamental na evolução deste campo de conhecimento 
e atuação. Do ponto de vista metodológico, Lucy Yardley (University of Southampton) acrescentou a urgência na superação das oposições entre paradigma interpretativo ou construtivista das abordagens qualitativas e o paradigma científico ou positivista das abordagens quantitativas.

Wendy Stainton Rogers (Open University), autora do livro The Psychology of Gender and Sexuality, criticou o enfoque patológico em estudos sobre a sexualidade humana, sobretudo aqueles voltados para a masculinidade, os quais reduzem gênero a uma oposição binária, amplificando os estereótipos sexuais. Além de não contemplar as necessidades de compreensão da atualidade, tais pesquisas continuam a reproduzir o tradicional e restrito modelo biomédico.

Vale destacar ainda que, na ocasião, foi criada a International Society of Critical Health Psychology, cujo presidente indicado é o canadense Michael Murray. A Terceira Conferência Internacional com previsão para 2003 deverá ser realizada na Nova Zelândia e será organizada por Kerry Chamberlain (Massey University).

\section{INTERESSADO EM AGILIZAR A PUBLICAÇÃO DE SEU ARTIGO?}

\section{Informações e dicas para os autores sobre aspectos operacionais}

\section{O manuscrito é reencaminhado pelo autor em versão reformulada}

A produção gráfica do trabalho é executada através de editoração eletrônica, daí a exigência do exemplar em disquete, além de três exemplares em papel da versão reformulada. Quando a versão reformulada é aceita e são poucos os reparos, as correções necessárias são feitas na secretaria da revista. Com o disquete disponível o processamento pode ser imediatamente iniciado. Na falta de disquete não é possível o processamento de correções nem a preparação do manuscrito para editoração. Em suma, atraso para entrar no prelo.

\section{Informações e dicas para os autores com artigos no prelo}

\section{O manuscrito é encaminhado para editoração}

No caso de o manuscrito ser aceito para publicação, é esperada a participação do autor no processo de preparação do artigo na fase de editoração. A primeira prova do artigo, editada a partir da versão em disquete, é enviada para exame ao(s) autor(es). O prazo para devolução é de 48 horas. A obediência ao prazo permite a manutenção da composição prevista para o volume/número da revista. $\mathrm{O}$ atraso no envio da prova examinada pode implicar em mudanças na composição de um número no prelo. E pode resultar em atraso na edição final. 